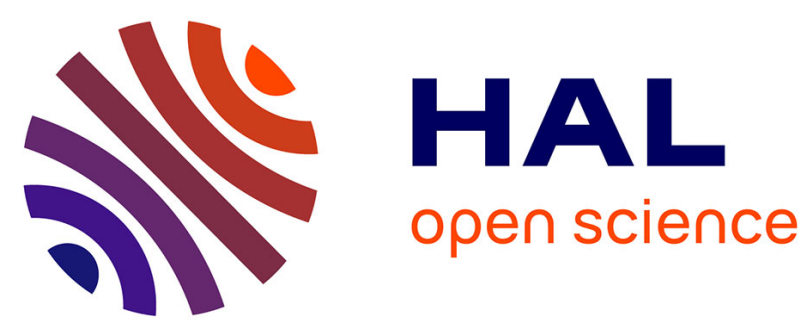

\title{
Association between organic food consumption and Metabolic Syndrome: cross-sectional results from the NutriNet-Santé study
}

Julia Baudry, Helene Lelong, Solia Adriouch, Chantal Julia, Benjamin Allès, Serge Hercberg, Mathilde Touvier, Denis Lairon, Pilar Galan, Emmanuelle Kesse-Guyot

\section{To cite this version:}

Julia Baudry, Helene Lelong, Solia Adriouch, Chantal Julia, Benjamin Allès, et al.. Association between organic food consumption and Metabolic Syndrome: cross-sectional results from the NutriNetSanté study. European Journal of Nutrition, 2017, 57 (7), pp.2477-2488. 10.1007/s00394-017-1520-1. hal-01794035

\section{HAL Id: hal-01794035 \\ https://hal-amu.archives-ouvertes.fr/hal-01794035}

Submitted on 17 May 2018

HAL is a multi-disciplinary open access archive for the deposit and dissemination of scientific research documents, whether they are published or not. The documents may come from teaching and research institutions in France or abroad, or from public or private research centers.
L'archive ouverte pluridisciplinaire HAL, est destinée au dépôt et à la diffusion de documents scientifiques de niveau recherche, publiés ou non, émanant des établissements d'enseignement et de recherche français ou étrangers, des laboratoires publics ou privés. 
Association between organic food consumption and Metabolic Syndrome: cross-sectional results from the NutriNet-Santé study

Julia Baudry ${ }^{1}$, , Hélène Lelong ${ }^{1}$, Solia Adriouch ${ }^{1}$, Chantal Julia ${ }^{1}$, Benjamin Allès ${ }^{1}$, Serge

Hercberg $^{1,2}$, Mathilde Touvier ${ }^{1}$, Denis Lairon ${ }^{3}$, Pilar Galan ${ }^{1}$, Emmanuelle Kesse-Guyot ${ }^{1}$

${ }^{1}$ Université Paris 13, Equipe de Recherche en Epidémiologie Nutritionnelle (EREN), Centre d'Epidémiologie et Statistiques Sorbonne Paris Cité, Inserm (U1153), Inra (U1125), Cnam, COMUE Sorbonne Paris Cité, F-93017 Bobigny, France

${ }^{2}$ Département de Santé Publique, Hôpital Avicenne, F-93017 Bobigny, France

${ }^{3}$ Aix Marseille Université, Nutrition Obésité et Risque Thrombotique (NORT), INRA 1260, INSERM UMR S 1062, Marseille, France

\section{*Corresponding author:}

Julia Baudry, Equipe de Recherche en Epidémiologie Nutritionnelle (EREN)

SMBH Université Paris 13, 74 rue Marcel Cachin, 93017 Bobigny, France.

Phone: +3314838 89 44; Fax: +3314838 89 31;

E-mail: j.baudry@eren.smbh.univ-paris13.fr

Running title: Organic food consumption and Metabolic Syndrome

\section{Manuscript word count: 4821}

\section{Abstract word count: 270}

\section{Acknowledgements}

We thank all the people who helped carry out the NutriNet-Santé study and all dedicated and conscientious volunteers. We especially thank Younes Esseddik, Paul Flanzy, Nathalie Arnault, Fabien Szabo, Laurent Bourhis and Cédric Agaesse.

\section{Funding}

The BioNutriNet project was supported by the French National Research Agency (Agence Nationale de la Recherche) in the context of the 2013 Programme de Recherche Systèmes Alimentaires Durables (ANR-13-ALID-0001). The NutriNet-Santé cohort study is funded by the 
following public institutions: Ministère de la Santé, Santé Publique France, Institut National de la Santé et de la Recherche Médicale (INSERM), Institut National de la Recherche Agronomique (INRA), Conservatoire National des Arts et Métiers (CNAM) and Paris 13 University. The funders had no role in study design, data collection and analysis, decision to publish, or preparation of the manuscript. 


\begin{abstract}
Purpose: Metabolic Syndrome (MetS), a multicomponent condition, is a cardiovascular disease predictor. Although exposure to agricultural pesticides has been suggested as a potential contributor to the rising rates of obesity, type 2 diabetes and other features of metabolic disorders, no studies have focused on the association between consumption of organic food (produced without synthetic pesticides) and MetS. We aimed to investigate the cross-sectional association between organic food consumption and MetS in French adults to determine whether it would be worth conducting further studies, particularly large prospective and randomised trials.

Methods: A total of 8,174 participants from the NutriNet-Santé study who attended a clinical visit and completed an organic food frequency questionnaire were included in this cross-sectional analysis. We evaluated the association between the proportion of organic food in the diet (overall and by food group) and MetS using Poisson regression models while adjusting for potential confounders.
\end{abstract}

Results: Higher organic food consumption was negatively associated with the prevalence of MetS: adjusted prevalence ratio was 0.69 (95\%CI: $0.61,0.78)$, when comparing the $3^{\text {rd }}$ tertile of proportion of organic food in the diet with the first one (p-value $<0.0001$ ). Higher consumption of organic plant-based foods was also related to a lower probability of having MetS. In addition, when stratifying by lifestyle factors (nutritional quality of the diet, smoking status, physical activity), a significant negative association was detected in each subgroup (p-values $<0.05$ ), except among smokers.

Conclusions: Our results showed that a higher organic food consumption was associated with a lower probability of having MetS. Additional prospective studies and randomised trials are required to ascertain the relationship between organic food consumption and metabolic disorders.

Keywords: metabolic syndrome, metabolic traits, organic food consumption, dietary pattern

Abbreviations: BMI, Body Mass Index; CI, Confidence Intervals; CNIL, National Commission on Informatics and Liberty; DBP, Diastolic Blood Pressure; EFSA, European Food Safety Authority; ENNS, French National Nutrition and Health Survey; HDL, High Density Protein; IRB, Institutional Review Board of the French Institute for Health and Medical Research; INSEE, French National Institute of Statistics and Economic Studies; IPAQ, International Physical 
Activity Questionnaire; LDL, Low Density Protein; MetS, Metabolic Syndrome; mPNNS-GS, modified Programme National Nutrition Guideline Score; Org-FFQ, organic Food Frequency Questionnaire; Persistent Organic Pollutants, POP; PUFA, Polyunsaturated Fatty Acids; PR, Prevalence Ratios; SBP, Systolic Blood Pressure 


\section{Introduction}

2 Metabolic Syndrome (MetS), a collection of metabolic abnormalities, is a clinical condition used

3 to identify individuals at increased risk of cardiovascular mortality early in the disease process

4 [1-4]. Features of MetS combine dyslipidaemia, elevated blood pressure and glycaemia, and 5 abdominal obesity [5]. The prevalence of MetS reached 25\% of the population in Europe [6], in

6 line with the rising rate of obesity and type-2 diabetes. In France, where the MetS appeared to be

7 lower than in most industrialised countries, MetS prevalence would be comprised between 14.1\%

8 and $21.1 \%$ depending on definitions used, according to the French National Nutrition and Health

9 Survey (ENNS) carried out in 2006-2007 [7].

11 Although the aetiology of MetS is complex, some major environmental risk factors are well12 known, and include diet [8-12], physical activity [13] or tobacco smoking [14]. While the role of 13 dietary patterns (e.g. vegetarian or Mediterranean diets [10-12, 15]) on the risk of onset of MetS 14 has been thoroughly investigated, no studies have taken into consideration the mode of food 15 production (i.e. organic or conventional farming practices) in the association between diet and 16 metabolic status.

18 Consumers are increasingly concerned about what they eat and about the potential harmful effects of pesticide residues on their health [16-18], and as a result, more and more are turning to organic food [19], since the use of synthetic pesticides and chemical fertilisers is prohibited by organic farming regulations [20]. The latest European Food safety Authority (EFSA) report on pesticide residues in food [21] indicates a lower dietary exposure to pesticides via organic foods than via conventional crop-based foods. In addition, a cross-over Australian study showed a drastic (about 90\%) reduction in urinary organophosphate exposure in adults after a change toward a $80 \%$ organic food-based diet [22], in line with several studies previously conducted among children [23-25]. Existing systematic reviews and meta-analyses comparing organically and conventionally produced foods also pointed differences in nutritional composition amongst which higher content in polyphenol compounds [26-29], antioxidants [26, 30-33] and vitamins $[26-28,30]$ in organic crops as well as the beneficial fatty acid profiles in organic dairy products $[27,31,32]$. They also found lower concentrations of nitrate $[26,27,30,33]$ and lower levels of iodine and selenium in organic milk [32]. Significantly lower concentrations of cadmium in 
32 organic food have also been reported [26] while no differences have been observed for other

33 toxic metals [28]. Although these findings overall argue for a more favourable nutritional

34 composition of organic products compared to conventional alternatives, the clinical relevance of

35 these differences, however, remains uncertain.

37 The study of the impact of organic food consumption on metabolic status is of high interest as several epidemiological studies have suggested a link between pesticide exposure and metabolic disorders [34-37]. In addition to well-established contributors to cardio-metabolic diseases (such as lack of physical activity and energy overconsumption), newly identified potential risk factors include endocrine disrupting pesticides such as organochlorides, organophosphates, carbamates and pyrethroids $[38,39]$. Besides, various nutritional factors - for which differences have been

43 observed between organic and conventional products - have been linked to a decreased risk for some cardiovascular outcomes (such as omega-3 polyunsaturated fatty acids (PUFA) [40, 41], polyphenols [42], several metal pollutants and more specifically cadmium [43] and more controversially nitrate and nitrite $[44,45])$.

Nonetheless, to our knowledge, the link between a diet largely based on organic foods (namely with a potential low pesticide exposure and potentially a more favourable nutritional profile) and metabolic status has never been explored. Studies evaluating the associations between obesity and organic food consumption are scarce; only three studies (two of which were conducted in the NutriNet-Santé cohort) have shown that regular organic food consumption was negatively related

\section{3 to obesity [46-48].}

Hence, the objective of the present study was to examine the specific relationship between organic food consumption (overall and by food groups) and the presence of MetS using a crosssectional design, among a large sample of adults residing in France from the NutriNet-Santé study. Through this exploratory analysis, we aimed to provide some evidence in the field of organic food consumption and metabolic disorders to determine whether this particular domain merits further investigation. 


\section{Methods}

64 Study population and design

65 This study is based on the NutriNet-Santé study data, an ongoing observational web-based cohort 66 study launched in May 2009. Its overall aim is to investigate the relationships between nutrition 67 and health as well as the determinants of dietary behaviours and nutritional status. The NutriNet68 Santé study's rationale, design, and methodology have been described elsewhere [49]. In brief, 69 upon enrolment in the NutriNet-Santé study and each year thereafter, participants are asked to 70 provide information on sociodemographic and various lifestyle factors, health status, physical 71 activity, anthropometric factors, and diet. The NutriNet-Santé study is conducted in accordance 72 with the Declaration of Helsinki, and all procedures were approved by the Institutional Review 73 Board of the French Institute for Health and Medical Research (IRB Inserm number 74 0000388FWA00005831) and the National Commission on Informatics and Liberty (CNIL numbers 908450 and 909216). Electronic informed consent was obtained from each participant (EudraCT no.2013-000929-31).

Additionally, in 2011-2014, the NutriNet-Santé participants were invited, on a voluntary basis, to attend a visit for biological sampling and clinical examination in one of the local centres

80 throughout France. Electronic and paper written informed consents were obtained from all 81 participants attending the visit. All procedures were approved by the 'Consultation Committee for 82 the Protection of Participants in Biomedical Research' (C09-42 on May 5th 2010) and the CNIL $83\left(n^{\circ} 1460707\right)$.

\section{Data collection}

86 Dietary data

87 Food and organic food consumption were assessed through a validated self-administered semi88 quantitative food frequency questionnaire [50], to which additional questions about frequencies 89 of consumption of organic foods were added (Org-FFQ). The Org-FFQ has been described in 90 details elsewhere [51]. Briefly, the Org-FFQ included 264 food and beverage items, coupled for 91 the most part with specified serving sizes. The questionnaire also included photographs for some 92 specific categories that are not usually consumed in predetermined portion. For each food item, 93 participants were asked to provide their consumption frequency over the past year (through a 
94 drop-down list including yearly, monthly, weekly or daily units) as well as the quantities

95 consumed. In addition, the frequency of organic food consumption was assessed using the

96 following statement: 'How often was the product of organic origin?'. Answers modalities were

97 assessed by a 5 frequency-categories scale with modalities from 'never' to 'always' (never,

98 rarely, half of time, often and always).

99

100 Modalities of frequencies of organic food consumption were translated into quantitative data by 101 attributing a weight of $0,0.25,0.5,0.75$ and 1 to the respective following categories: 'never', 102 'rarely', 'half the time', 'often' and 'always'. Thus, we calculated the proportion of organic food 103 in the whole diet by dividing the total organic food consumption (in grams per day) out of the 104 total consumption without water (in grams per day). We also calculated the proportion of organic 105 food in 16 main food groups among consumers. Nutrient intakes were assessed using a generic 106 food composition database (independent of the food production - organic or conventional), 107 specifically developed for the items of the Org-FFQ, which was based on the NutriNet-Santé 108 original food composition table that includes more than 3000 items [52].

109

110 In addition, we computed the mPNNS-GS (modified Programme National Nutrition Santé 111 Guideline Score), a diet quality score based on adherence to the French dietary guidelines 112 excluding the physical activity component [53].

113 Information on anteriority of organic food consumption (referring to the number of years for 114 which participants have been consuming organic products) was collected via a questionnaire 115 pertaining to attitudes towards organic food administered in July 2014.

117 Covariates

118 At baseline and during follow-up phases, self-administered questionnaires were used to collect 119 information on sociodemographic factors and lifestyle, and medication use, including sex, age, 120 education (highest degree achieved), marital status, number of children, smoking habits, income, 121 place of residence, physical activity (as assessed by the International Physical Activity 122 Questionnaire (IPAQ) [54, 55]), and antidiabetic, antihypertensive and lipid-lowering 123 medications. Monthly income per household unit was calculated using INSEE (French National 124 Institute of Statistics and Economic Studies) calculation [56]. 
Clinical data assessment

126 During the clinical examination, anthropometrics and blood pressure were measured by trained personnel using standardised protocols. Systolic and diastolic blood pressures (SBP and DBP

128 respectively) were measured 3 times at 1-minute intervals in a seated position after lying down

129 for 5 minutes using an automatic validated device (HEM-7015IT; OMRON, Rosny-sous-Bois, 130 France). Mean values were calculated for the analyses. The clinical examination also comprised 131 measures of weight, height, and waist circumference. Weight was measured once using an 132 electronic scale (BC-418MA; TANITA, Tokyo, Japan) with participants only wearing underwear 133 and barefoot. Height was measured once with a wall-mounted measuring rod. Body mass index 134 (BMI in $\mathrm{kg} / \mathrm{m}^{2}$ ) was calculated. Waist circumference was measured as the circumference midway 135 between the lower ribs and iliac crests.

Biological data assessment

138 During the visit, blood samples were collected after at least a $6 \mathrm{~h}$-fast period and centralised and 139 analysed at a single laboratory (IRSA, Tours, France). Total serum cholesterol (cholesterol oxidase C8000, Abbott), HDL-cholesterol (High Density Protein - cholesterol) (direct accelerator C8000, Abbott), serum triglycerides (glycerol kinase C8000, Abbott) and fasting blood glucose were measured (hexokinase on C 8000 automat, Abbott, Suresnes, France). LDL-cholesterol (Low Density Protein - cholesterol) was calculated using the Friedwald formula [57].

\section{Definition of MetS}

146 Individuals defined as presenting MetS were those having any three of the following five criteria 147 according to the 2009 interim consensus statement [5]:

148 - abdominal obesity (waist circumference $\geq 94 \mathrm{~cm}$ for men and $\geq 80 \mathrm{~cm}$ for women),

149 - elevated blood pressure (SBP/DBP $\geq 130 / 85 \mathrm{mmHg}$ or antihypertensive medication),

150 - elevated triglyceridemia ( $\geq 150 \mathrm{mg} / \mathrm{dL}$ or fibrate medication),

151 - low HDL-cholesterolemia ( $<40 \mathrm{mg} / \mathrm{dL}$ for men or $<50 \mathrm{mg} / \mathrm{dL}$ for women),

152 - elevated glycaemia (fasting glycaemia $>100 \mathrm{mg} / \mathrm{dL}$ or antidiabetic medication). 


\section{Statistical analysis}

Among respondents to the Org-FFQ $(n=33,384)$, we selected those who attended the medical visit $(\mathrm{n}=9,373)$, with valid anthropometric and biological data $(\mathrm{n}=8,354)$, with available covariates, which led to a final sample of 8,174 individuals (2,602 men and 5,572 women).

Participant characteristics (sociodemographic and dietary traits) were compared across tertiles of proportion of organic food in the diet using ANCOVA with linear contrast (continuous variables) and Cochran-Mantel-Haenszel trend test (categorical variables). Values are reported as means with standard deviations (SD) or percent as appropriate. Based on the source population (respondents to the Org-FFQ), excluded and included participants were compared using MannWhitney $\mathrm{U}$ tests and $\mathrm{Chi}^{2}$-tests.

A total of $16.7 \%$ of subjects met the criteria for MetS (23.8\% in men and $13.4 \%$ in women) in the study sample. Since the occurrence of the dependent variable exceeded $10 \%$, odds ratios from standard logistic regressions could not be considered as appropriate proxies for relative risks [58]. We therefore used an alternative method recommended by Zou et al. [59] based on Poisson regression models with robust errors to evaluate the association between tertiles of proportion of organic food in the diet, as well as tertiles of proportion of organic food in 16 food groups, and having MetS (binary dependent variable). The lower tertile of proportion of organic food in the diet was considered as reference category. We reported Prevalence Ratios (PR) and 95\% Confidence Interval $(95 \% \mathrm{CI})$ as well as P-values from linear contrast.

A first model was crude (model 1). A second model (main model, model 2) was adjusted for age, sex, educational level, monthly income, physical activity, smoking habits, season of blood sampling, time lag between organic food questionnaire completion and clinical visit, occupational status, location, energy intake and overall dietary quality (reflected by the mPNNS-GS as a continuous variable). A supplementary model (model 3) was further controlled for BMI to determine the association of organic food consumption with MetS beyond adiposity. An additional model (model 4) was also performed by adding to the main model the anteriority of organic food consumption (as a categorical variable: non-organic food consumption, organic food consumption for less than 5 years, organic food consumption for more than 5 years). The models 
185 pertaining to the association between the proportion of organic food in several food groups and

186 MetS were additionally adjusted for the corresponding food group consumption.

188 Furthermore, in an attempt to distinguish the role of organic food from that of potential correlated

189 lifestyles, we investigated the association between the proportion of organic food in the diet (as a continuous variable) and having MetS stratified by various behavioural factors: overall nutritional quality of the diet (using tertiles of mPNNS-GS), smoking habits and physical activity.

ANCOVA models were also performed to evaluate the relationship between the proportion of organic food in the diet and various metabolic traits (fasting blood glucose, waist circumference, SBP, DBP, serum triglycerides and HDL-cholesterol) among sub-samples who were not taking any related medications for the specific outcome. To improve normality, anthropometric variables and biomarkers were logarithmically transformed before analysis and adjusted geometric means $(95 \% \mathrm{CI})$ across tertiles of proportion of organic food in the diet are provided. Same confounding covariates as those previously described for MetS in model 2 were used.

All tests of significance were two-sided, and the type I error was set at 5\%. All analyses were performed using SAS software (version 9.4, SAS Institute, Inc.).

\section{Results}

205 Participants included in our study were older (58.16 \pm 12.34 y vs. $53.20 \pm 14.07$ y), more often men (32\% vs. $25 \%)$ and had more frequently a monthly income higher than $2700 €$ per household unit (32\% vs. 39\%) than respondents to the Org-FFQ excluded from the analysis (data not 208 tabulated).

\section{Characteristics of the participants}

211 Main characteristics of the study sample across tertiles of proportion of organic food in the diet 212 are presented in Table 1. Low organic food consumers (tertile 1) consumed no or very little 213 organic food while, in tertile 3, organic food made up, on average, $0.62(0.18)$ of the diet.

214 Compared to low organic food consumers, high organic food consumers were less often men, 215 younger and more often highly educated. No statistically significant difference was observed 
216 concerning monthly income per household unit across tertiles of proportion of organic food in the

217 diet. High organic food consumers also lived less frequently in a population-dense urban unit

218 (>200000 inhabitants) than low organic food consumers. They were also more often never 219 smokers and more frequently presented a high physical activity. Higher organic food 220 consumption was also associated with a higher overall nutritional quality of the diet, lower 221 alcohol consumption and a lower body mass index.

Association between the proportion of organic food in the diet and MetS

224 Table 2 shows the association between tertiles of proportion of organic food in the diet and 225 MetS. In the main model (model 2), higher organic food consumption was associated with a 226 lower probability of having MetS $\left(\mathrm{PR}_{\text {tertile3 vs. tertile } 1}=0.69,95 \% \mathrm{CI}=0.61-0.78\right.$; $\mathrm{p}$ for linear contrast $<0.0001)$. The association was attenuated but persisted even after controlling for BMI ( $\mathrm{PR}_{\text {tertile3 vs. }}$ tertile $1=0.86,95 \% \mathrm{CI}=0.76-0.98$; $\mathrm{p}$ for linear contrast $=0.02$ ) (model 3) or for the anteriority of organic food consumption $\left(\mathrm{PR}_{\text {tertile3 }}\right.$ vs. tertile $=0.69,95 \% \mathrm{CI}=0.59-0.80 ; \mathrm{p}$ for linear contrast

\section{Association between the proportion of organic food according to food groups and MetS}

233 Table 3 shows a marked negative association between an increased consumption of products

234 from organic origin for plant food groups (including fruit and vegetables, starchy foods, whole235 grain products and oil; all $\mathrm{p}$ for linear contrast $\leq 0.0005$ ) as well as sweetened foods and non236 alcoholic beverages ( $\mathrm{p}$ for linear contrast $<0.0001$ ) and MetS. Similar results were observed, but 237 to a lesser extent, for eggs, dairy products and fast food. In contrast, no significant association 238 was found in the cases of seafood and meat, poultry and processed meat ( $\mathrm{p}>0.05)$.

240 Association between the proportion of organic food in the diet and metabolic components

241 In the fully adjusted model, among subgroups of individuals who were not taking any related 242 medication for the specific outcome, higher organic food consumption was significantly 243 associated with lower fasting blood glucose, waist circumference, SBP and DBP, and 244 triglycerides (all $\mathrm{p}$ for linear contrast $<0.05$ ), but not with HDL-cholesterol (Table 4). 
246 Association between the proportion of organic food in the diet and MetS according to overall

247 dietary quality, smoking status and physical activity

248 Stratified analyses are illustrated in Figure 1. After stratifying by tertiles of the mPNNS-GS

249 (reflecting overall dietary quality), higher organic food consumption (modelled as a continuous

250 variable) was negatively associated with MetS, regardless the level of dietary quality, when

251 adjusting for sociodemographic and lifestyle variables. Similar results were obtained when

252 stratifying by other lifestyle factors including smoking status and physical activity level, except

253 among current smokers.

\section{Discussion}

256 In this cross-sectional study, we observed that a higher organic food consumption (i.e. a 257 proportion of organic food in the diet $>38 \%$, corresponding to the $3^{\text {rd }}$ tertile) was associated with 258 a lower probability of having MetS as well as lower levels of glycaemia, blood pressure, 259 triglycerides, and waist circumference after adjustment for the major known confounding factors.

260 No significant association was observed with the HDL-cholesterol. The negative association was 261 observed, in particular, when the proportion of plant food from organic sources increased, and 262 persisted among different subgroups of the study sample.

263 To the best of our knowledge, no studies had previously investigated the specific association 264 between organic food consumption and metabolic disorders, and MetS in particular.

265 Some data is however available regarding anthropometric traits of organic food consumers. A 266 study conducted in Germany showed that buyers of organic food exhibited lower body weight 267 compared to non-buyers [47]. However, the primary aim of that study was descriptive and did not 268 take into account potential confounding factors. Hence, lower body weights among frequent 269 buyers of organic foods could be attributable to healthier lifestyles rather than to differences in 270 consumption of organic and conventional foods. Previous cross-sectional findings from the 271 NutriNet-Santé have also highlighted a negative association between regular organic food 272 consumption and BMI in fully adjusted models [46]. More recently, in a prospective study 273 carried out in the same cohort [48], we showed, after controlling for major confounders, that an 274 increase of self-reported organic food frequency was associated with a significantly lower risk of 275 overweight and obesity. 
276 In the present work, associations between high organic food consumption and the prevalence of

277 MetS remained significant even after carefully adjusting for a wide range of confounders

278 (including overall dietary quality, physical activity, sex, and BMI).

280 A potential hypothesis explaining, at least in part, our findings may be the reduced dietary exposure of high organic food consumers to synthetic pesticides. Indeed, as European Union

282 legislation allows only a very limited number of natural pesticides to be used in organic food 283 production, the occurrence of synthetic pesticide residues in organic crops is much lower than in conventional crops $[21,26]$. In the last report of the EFSA, $15.5 \%$ of organic foods contained pesticide residues ( $0.8 \%$ above the Maximum Residue Level) vs. $44.4 \%$ of conventional products (2.7\% above the Maximum Residue Level) [21]. It can thus be hypothesised that individuals who consume a high level of organic food in their diet would reduce their overall dietary exposure to pesticides, as highlighted in studies conducted in adults [22, 60] or in children [23, 24].

Several epidemiological studies have suggested a link between pesticide exposure, obesity and metabolic disorders. Our findings may be interpreted in light of some studies which showed, for instance, a positive association between an increased risk for abnormal glucose regulation and exposure to pyrethroids [61]. The findings from the Agricultural Health cohort study, conducted in 30,000 farmers in the US, suggested that long-term occupational exposure, in particular organochlorine and organophosphate insecticide exposure, could be associated with increased risk of developing diabetes [62]. However, epidemiological studies about the impact of exposure to organophosphorus compounds (widely used in agriculture) in the general population, on metabolic status are lacking.

Among potential mechanisms, it has been reported that exposure to endocrine disruptors such as various currently used pesticides, i.e. organophosphates and pyrethroids would impact glucose

302 homeostasis and fat metabolism [38, 63]. Organophosphorus compounds would disrupt 303 carbohydrate homeostasis, resulting in elevated serum glucose levels [64]. Among disrupting 304 effects of the organophosphates, mechanistic pathways may involve oxidative damage and 305 inflammatory cytokines, possibly leading to compensatory responses accompanied with reduced insulin signalling in insulin sensitive organs [63]. 
307 This seems in agreement with our findings concerning biomarkers related to glucose and fat

308 metabolism, namely glycaemia and triglyceride levels. As regards blood pressure, to our 309 knowledge, no studies have investigated the specific association between exposure to widely used 310 pesticides and blood pressure. Thus experimental and epidemiological data focusing on effects of 311 organophosphate, pyrethroid or carbamate exposure and their synergistic association to 312 hypertension risks are necessary. We did not find a significant higher level of HDL-cholesterol in 313 individuals with higher organic food consumption after controlling for main confounding factors, 314 in line with the few available data regarding dietary pesticide exposure and this specific 315 biomarker.

316 Moreover, in addition to the potential effects of dietary pesticide exposure, mainly through 317 conventional plant-food consumption, on cardiometabolic disorders, our results can also be 318 interpreted in light of findings of a study carried out in rats which found overall better health and 319 physiological parameters among animals fed with an organic diet, of which higher concentrations 320 of polyphenols, plasma glucose, leptin or insulin-like growth factor 1 [65].

321 In addition, our analyses interestingly showed a negative association between higher 322 consumption of plant-based foods from organic origin and MetS while no association was 323 detected in the case of meat, poultry and processed meat.

324 These results can be considered in the light of the EFSA report [21] which showed that about half 325 plant food samples were contaminated by pesticide residues and that Maximum Residue Levels 326 were frequently exceeded for some plant-based products (e.g. strawberries, lettuce, apples or 327 oats) while this was not the case for animal-based foods like pork meat or cow milk. Thus, 328 conventional foods from plant origin would be the major contributors to current dietary pesticide 329 exposure, unlike animal-based foods.

330 Interestingly, we found significant negative associations between MetS prevalence and increasing 331 consumption of dairy products and eggs. These findings can be interpreted in light of studies 332 reporting more favourable fatty acid compositions in organic dairy products [31, 32]. Indeed, 333 recent meta-analyses have indicated that organic milk [32], and potentially organic meat [66], 334 contained a higher amount of omega-3 fatty acids, which are main components of a beneficial 335 diet for the cardiovascular system, compared to conventional products. Switch from conventional 336 to organic dairy and meat products could therefore lead to higher amounts of omega-3 fatty acids 337 and in turn positively affect cardiometabolic status. However, it is difficult to conclude to the 
338 nutritional significance of these differences on health, as these increases remain probably modest

339 and their effects unknown.

341 It should be borne in mind that high organic food consumers are high consumers of fruit, 342 vegetables and whole-grain products [47, 53]. Plant-based diets have also been associated with 343 reduced risk of having MetS $[10,15]$. In order to take into account the healthier dietary patterns 344 of high organic food consumers, as well as other potentially healthy lifestyle factors that play a 345 role in the development of MetS, we conducted stratified analyses, allowing to partially 346 overcome the 'nutritional' role of dietary patterns. Except in smokers, a higher proportion of 347 organic food in the diet was negatively related to MetS, whatever the subgroups considered. In 348 particular, the association was observed across all subgroups. Among smokers, no association 349 was observed between organic food consumption and MetS. One explanation might be that the 350 tobacco risk factor prevails, and in turn, in this 'high risk subgroup', the consumption of organic 351 food could play a minor role. Another explanation might be the relatively small size of that 352 specific subgroup. The non-significant result may therefore be related to limited statistical power.

\section{Limitations and strengths}

355 A major limitation of this study includes its cross-sectional design, restricting causal inference. 356 Although we adjusted for a large number of cofounding factors including variables related to 357 healthy lifestyles, we cannot omit the residual confounding due to the specific profiles of high 358 organic food consumers $(36,37)$. In addition, the NutriNet-Santé participants are more interested 359 in nutrition and health topics than the general population. Specifically, the participants of the 360 NutriNet-Santé study exhibit specific sociodemographic profiles [67] and healthier dietary habits

361 [68] than the general population. Besides, organic food consumption was assessed using a self362 administered food frequency questionnaire which is prone to measurement error. This has also 363 probably led to an overestimation of the consumption in particular for organic food [51]. Finally, 364 we did not have data regarding genetic factors that can play a role in the onset of MetS. Caution 365 is therefore needed when generalising the results.

367 Important strengths should also be acknowledged. We used accurate biological measures 368 (performed in a single laboratory) and clinical data (assessed by trained technicians using 
369 standardised procedures). The use of the Org-FFQ permitted to obtain detailed data on food

370 consumption, including information on the usual proportion coming from organic sources of

371 several food groups, within the overall diet. The use of a wide range of covariables, including 372 sociodemographic and lifestyle variables, enabled us to precisely characterise the individuals of

373 our study. Furthermore, the large size of the sample enabled us to conduct stratified analyses with

374 a sufficient statistical power, and to have a wide diversity of profiles.

376 Conclusion

377 In conclusion, our results provide the first insights into the undocumented research field of 378 metabolic health and organic food consumption. Our findings show that the highest the 379 consumption of organic food, the lowest the probability of having MetS. The associations that 380 were observed merit future investigation, and bolster the argument for the conduction of well381 designed randomised controlled trials. Besides, further prospective research based on accurate 382 data with regard to the nature of foods consumed is also needed to confirm these findings and 383 assess the long-term effects of organic food consumption on metabolic disorders. In a context of 384 tremendous growth of organic food consumption and where cardiovascular diseases remain the 385 first cause of mortality worldwide, these findings could be of major interest to drive the design of 386 future public health policies. 


\section{Contribution statement}

SH, PG, DL and EKG conceived and designed research; JB performed the statistical analysis and wrote the article; JB, HL, SA, CJ, BA, SH, MT, DL, PG and EKG were involved in revising the work critically for important intellectual content; JB had primary responsibility for final content. All authors read and approved the final manuscript.

\section{Conflicts of interest}

None of the authors declare any conflicts of interest. 


\section{References}

1. Galassi A, Reynolds K, He J (2006) Metabolic Syndrome and Risk of Cardiovascular Disease: A Meta-Analysis. Am J Med 119:812-819. doi: 10.1016/j.amjmed.2006.02.031

2. Gami AS, Witt BJ, Howard DE, et al (2007) Metabolic Syndrome and Risk of Incident Cardiovascular Events and Death. J Am Coll Cardiol 49:403-414. doi:

10.1016/j.jacc.2006.09.032

3. Wang J, Ruotsalainen S, Moilanen L, et al (2007) The metabolic syndrome predicts cardiovascular mortality: a 13-year follow-up study in elderly non-diabetic Finns. Eur Heart J 28:857-864. doi: 10.1093/eurheartj/eh1524

4. Benetos A, Thomas F, Pannier B, et al (2008) All-Cause and Cardiovascular Mortality Using the Different Definitions of Metabolic Syndrome. Am J Cardiol 102:188-191. doi: 10.1016/j.amjcard.2008.03.037

5. Alberti KGMM, Eckel RH, Grundy SM, et al (2009) Harmonizing the Metabolic Syndrome: A Joint Interim Statement of the International Diabetes Federation Task Force on Epidemiology and Prevention; National Heart, Lung, and Blood Institute; American Heart Association; World Heart Federation; International Atherosclerosis Society; and International Association for the Study of Obesity. Circulation 120:1640-1645. doi: 10.1161/CIRCULATIONAHA.109.192644

6. Grundy SM (2008) Metabolic Syndrome Pandemic. Arterioscler Thromb Vasc Biol 28:629636. doi: 10.1161/ATVBAHA.107.151092

7. Vernay M, Salanave B, de Peretti C, et al (2013) Metabolic syndrome and socioeconomic status in France: The French Nutrition and Health Survey (ENNS, 2006-2007). Int J Public Health 58:855-864. doi: 10.1007/s00038-013-0501-2

8. Nicklas TA, O’Neil CE, Fulgoni VL (2012) Diet Quality Is Inversely Related to Cardiovascular Risk Factors in Adults. J Nutr 142:2112-2118. doi: 10.3945/jn.112.164889

9. Lassale C, Galan P, Julia C, et al (2013) Association between Adherence to Nutritional Guidelines, the Metabolic Syndrome and Adiposity Markers in a French Adult General Population. PLoS ONE 8:e76349. doi: 10.1371/journal.pone.0076349

10. Kesse-Guyot E, Ahluwalia N, Lassale C, et al (2013) Adherence to Mediterranean diet reduces the risk of metabolic syndrome: A 6-year prospective study. Nutr Metab Cardiovasc Dis 23:677-683. doi: 10.1016/j.numecd.2012.02.005

11. Sabaté J, Wien M (2015) A perspective on vegetarian dietary patterns and risk of metabolic syndrome. Br J Nutr 113:S136-S143. doi: 10.1017/S0007114514004139 
12. Veissi M, Anari R, Amani R, et al (2016) Mediterranean diet and metabolic syndrome prevalence in type 2 diabetes patients in Ahvaz, southwest of Iran. Diabetes Metab Syndr Clin Res Rev 10:S26-S29. doi: 10.1016/j.dsx.2016.01.015

13. He D, Xi B, Xue J, et al (2014) Association between leisure time physical activity and metabolic syndrome: a meta-analysis of prospective cohort studies. Endocrine 46:231-240. doi: 10.1007/s12020-013-0110-0

14. Weitzman M (2005) Tobacco Smoke Exposure Is Associated With the Metabolic Syndrome in Adolescents. Circulation 112:862-869. doi: 10.1161/CIRCULATIONAHA.104.520650

15. Turner-McGrievy G, Harris M (2014) Key Elements of Plant-Based Diets Associated with Reduced Risk of Metabolic Syndrome. Curr Diab Rep. doi: 10.1007/s11892-014-0524-y

16. Aertsens J, Verbeke W, Mondelaers K, Van Huylenbroeck G (2009) Personal determinants of organic food consumption: a review. Br Food J 111:1140-1167. doi: $10.1108 / 00070700910992961$

17. Dickson-Spillmann M, Siegrist M, Keller C (2011) Attitudes toward chemicals are associated with preference for natural food. Food Qual Prefer 22:149-156. doi: 10.1016/j.foodqual.2010.09.001

18. Michaelidou N, Hassan LM (2008) The role of health consciousness, food safety concern and ethical identity on attitudes and intentions towards organic food. Int J Consum Stud 32:163-170. doi: 10.1111/j.1470-6431.2007.00619.x

19. Agence Bio/CSA (2016) Baromètre de consommation et de perception des produits biologiques en France, 13ème édition.

http://www.agencebio.org/sites/default/files/upload/documents/4_Chiffres/BarometreConso/ 1400610_agence_bio_rapport_2015_vp.pdf. Accessed 11 Aug 2016

20. (2007) Règlement (CE) No 834/2007 du Conseil.

21. European Food Safety Authority (2015) The 2013 European Union report on pesticide residues in food: The 2013 European Union report on pesticide residues. EFSA J 13:4038. doi: $10.2903 /$ j.efsa.2015.4038

22. Oates L, Cohen M, Braun L, et al (2014) Reduction in urinary organophosphate pesticide metabolites in adults after a week-long organic diet. Environ Res 132:105-111. doi: 10.1016/j.envres.2014.03.021

23. Curl CL, Fenske RA, Elgethun K (2002) Organophosphorus Pesticide Exposure of Urban and Suburban Preschool Children with Organic and Conventional Diets. Environ Health Perspect 111:377-382. doi: 10.1289/ehp.5754

24. Bradman A, Quirós-Alcalá L, Castorina R, et al (2015) Effect of Organic Diet Intervention on Pesticide Exposures in Young Children Living in Low-Income Urban and Agricultural Communities. Environ Health Perspect. doi: 10.1289/ehp. 1408660 
25. Lu C, Toepel K, Irish R, et al (2006) Organic Diets Significantly Lower Children's Dietary Exposure to Organophosphorus Pesticides. Environ Health Perspect 114:260-263. doi: 10.1289/ehp. 8418

26. Barański M, Średnicka-Tober D, Volakakis N, et al (2014) Higher antioxidant and lower cadmium concentrations and lower incidence of pesticide residues in organically grown crops: a systematic literature review and meta-analyses. Br J Nutr 1-18. doi: $10.1017 / \mathrm{S} 0007114514001366$

27. Brantsæter AL, Ydersbond TA, Hoppin JA, et al (2017) Organic Food in the Diet: Exposure and Health Implications. Annu Rev Public Health 38:295-313. doi: 10.1146/annurevpublhealth-031816-044437

28. Mie A, Kesse-Guyot E, Rembiałkowska E, et al (2016) Gunnars-son S. Human health implications of organic food and organic agriculture.

29. Smith-Spangler C, Brandeau ML, Hunter GE, et al (2012) Are Organic Foods Safer or Healthier Than Conventional Alternatives?A Systematic Review. Ann Intern Med 157:348366. doi: 10.7326/0003-4819-157-5-201209040-00007

30. Brandt K, Leifert C, Sanderson R, Seal CJ (2011) Agroecosystem Management and Nutritional Quality of Plant Foods: The Case of Organic Fruits and Vegetables. Crit Rev Plant Sci 30:177-197. doi: 10.1080/07352689.2011.554417

31. Palupi E, Jayanegara A, Ploeger A, Kahl J (2012) Comparison of nutritional quality between conventional and organic dairy products: a meta-analysis. J Sci Food Agric 92:2774-2781. doi: 10.1002/jsfa.5639

32. Średnicka-Tober D, Barański M, Seal CJ, et al (2016) Higher PUFA and n-3 PUFA, conjugated linoleic acid, $\alpha$-tocopherol and iron, but lower iodine and selenium concentrations in organic milk: a systematic literature review and meta- and redundancy analyses. Br J Nutr 115:1043-1060. doi: 10.1017/S0007114516000349

33. Lairon D (2010) Nutritional quality and safety of organic food. A review. Agron Sustain Dev 30:33-41. doi: 10.1051/agro/2009019

34. Evangelou E, Ntritsos G, Chondrogiorgi M, et al (2016) Exposure to pesticides and diabetes: A systematic review and meta-analysis. Environ Int 91:60-68. doi: 10.1016/j.envint.2016.02.013

35. Nicolopoulou-Stamati P, Maipas S, Kotampasi C, et al (2016) Chemical Pesticides and Human Health: The Urgent Need for a New Concept in Agriculture. Front Public Health. doi: 10.3389/fpubh.2016.00148

36. Kim K-H, Kabir E, Jahan SA (2017) Exposure to pesticides and the associated human health effects. Sci Total Environ 575:525-535. doi: 10.1016/j.scitotenv.2016.09.009 
37. Mostafalou S, Abdollahi M (2017) Pesticides: an update of human exposure and toxicity. Arch Toxicol 91:549-599. doi: 10.1007/s00204-016-1849-x

38. Collectif INSERM (2013) Pesticides : Effets sur la santé, une expertise collective de l'Inserm. In: Salle Presse Inserm. http://presse.inserm.fr/pesticides-effets-sur-la-sante-uneexpertise-collective-de-linserm/8463/. Accessed 21 Aug 2016

39. Mnif W, Hassine AIH, Bouaziz A, et al (2011) Effect of Endocrine Disruptor Pesticides: A Review. Int J Environ Res Public Health 8:2265-2303. doi: 10.3390/ijerph8062265

40. Mozaffarian D, Wu JHY (2011) Omega-3 Fatty Acids and Cardiovascular Disease. J Am Coll Cardiol 58:2047-2067. doi: 10.1016/j.jacc.2011.06.063

41. Pan A, Chen M, Chowdhury R, et al (2012) -Linolenic acid and risk of cardiovascular disease: a systematic review and meta-analysis. Am J Clin Nutr 96:1262-1273. doi: 10.3945/ajcn.112.044040

42. Del Rio D, Rodriguez-Mateos A, Spencer JPE, et al (2013) Dietary (Poly)phenolics in Human Health: Structures, Bioavailability, and Evidence of Protective Effects Against Chronic Diseases. Antioxid Redox Signal 18:1818-1892. doi: 10.1089/ars.2012.4581

43. Solenkova NV, Newman JD, Berger JS, et al (2014) Metal pollutants and cardiovascular disease: Mechanisms and consequences of exposure. Am Heart J 168:812-822. doi: 10.1016/j.ahj.2014.07.007

44. Hord NG, Conley MN (2017) Regulation of Dietary Nitrate and Nitrite: Balancing Essential Physiological Roles with Potential Health Risks. In: Bryan NS, Loscalzo J (eds) Nitrite Nitrate Hum. Health Dis. Springer International Publishing, Cham, pp 153-162

45. Ahluwalia A, Gladwin M, Coleman GD, et al (2016) Dietary Nitrate and the Epidemiology of Cardiovascular Disease: Report From a National Heart, Lung, and Blood Institute Workshop. J Am Heart Assoc 5:e003402. doi: 10.1161/JAHA.116.003402

46. Kesse-Guyot E, Péneau S, Méjean C, et al (2013) Profiles of Organic Food Consumers in a Large Sample of French Adults: Results from the Nutrinet-Santé Cohort Study. PLoS ONE 8:e76998. doi: 10.1371/journal.pone.0076998

47. Eisinger-Watzl M, Wittig F, Heuer T, Hoffmann I (2015) Customers Purchasing Organic Food - Do They Live Healthier? Results of the German National Nutrition Survey II. Eur J Nutr Food Saf 5:59-71. doi: 10.9734/EJNFS/2015/12734

48. Kesse-Guyot E, Baudry J, Assmann KE, et al (2017) Prospective association between consumption frequency of organic food and body weight change, risk of overweight or obesity: Results from the NutriNet-Santé Study. Br. J. Nutr.

49. Hercberg S, Castetbon K, Czernichow S, et al (2010) The Nutrinet-Santé Study: a webbased prospective study on the relationship between nutrition and health and determinants 
of dietary patterns and nutritional status. BMC Public Health 10:242. doi: 10.1186/14712458-10-242

50. Kesse-Guyot E, Castetbon K, Touvier M, et al (2010) Relative validity and reproducibility of a food frequency questionnaire designed for French adults. Ann Nutr Metab 57:153-162. doi: $10.1159 / 000321680$

51. Baudry J, Méjean C, Allès B, et al (2015) Contribution of Organic Food to the Diet in a Large Sample of French Adults (the NutriNet-Santé Cohort Study). Nutrients 7:8615-8632. doi: $10.3390 / \mathrm{nu} 7105417$

52. (2013) NutriNet-Santé coordination. Table de composition des aliments.

53. Baudry J, Allès B, Péneau S, et al (2016) Dietary intakes and diet quality according to levels of organic food consumption by French adults: cross-sectional findings from the NutriNetSanté Cohort Study. Public Health Nutr 1-11. doi: 10.1017/S1368980016002718

54. Hagströmer M, Oja P, Sjöström M (2006) The International Physical Activity Questionnaire (IPAQ): a study of concurrent and construct validity. Public Health Nutr 9:755-762.

55. Craig CL, Marshall AL, Sjöström M, et al (2003) International physical activity questionnaire: 12-country reliability and validity. Med Sci Sports Exerc 35:1381-1395. doi: 10.1249/01.MSS.0000078924.61453.FB

56. INSEE (2009) Definitions and methods.

57. Planella T, Cortés M, Martínez-Brú C, et al (1997) Calculation of LDL-cholesterol by using apolipoprotein B for classification of nonchylomicronemic dyslipemia. Clin Chem 43:808815.

58. Zhang J, Yu KF (1998) What's the Relative Risk?: A Method of Correcting the Odds Ratio in Cohort Studies of Common Outcomes. JAMA 280:1690. doi: 10.1001/jama.280.19.1690

59. Zou G (2004) A Modified Poisson Regression Approach to Prospective Studies with Binary Data. Am J Epidemiol 159:702-706. doi: 10.1093/aje/kwh090

60. Curl CL, Beresford SAA, Fenske RA, et al (2015) Estimating Pesticide Exposure from Dietary Intake and Organic Food Choices: The Multi-Ethnic Study of Atherosclerosis (MESA). Environ Health Perspect. doi: 10.1289/ehp.1408197

61. Wang J, Zhu Y, Cai X, et al (2011) Abnormal glucose regulation in pyrethroid pesticide factory workers. Chemosphere 82:1080-1082. doi: 10.1016/j.chemosphere.2010.10.065

62. Montgomery MP, Kamel F, Saldana TM, et al (2008) Incident diabetes and pesticide exposure among licensed pesticide applicators: Agricultural Health Study, 1993-2003. Am J Epidemiol 167:1235-1246. doi: 10.1093/aje/kwn028 
63. Mostafalou S, Abdollahi M (2013) Pesticides and human chronic diseases: evidences, mechanisms, and perspectives. Toxicol Appl Pharmacol 268:157-177. doi:

10.1016/j.taap.2013.01.025

64. Androutsopoulos VP, Hernandez AF, Liesivuori J, Tsatsakis AM (2013) A mechanistic overview of health associated effects of low levels of organochlorine and organophosphorous pesticides. Toxicology 307:89-94. doi: 10.1016/j.tox.2012.09.011

65. Średnicka-Tober D, Barański M, Gromadzka-Ostrowska J, et al (2013) Effect of Crop Protection and Fertilization Regimes Used in Organic and Conventional Production Systems on Feed Composition and Physiological Parameters in Rats. J Agric Food Chem 61:10171029. doi: $10.1021 /$ jf303978n

66. Średnicka-Tober D, Barański M, Seal C, et al (2016) Composition differences between organic and conventional meat: a systematic literature review and meta-analysis. Br J Nutr 115:994-1011. doi: 10.1017/S0007114515005073

67. Andreeva V, Salanave B, Castetbon K, et al (2015) Comparison of the sociodemographic characteristics of the large NutriNet-Santé e-cohort with French Census data: the issue of volunteer bias revisited. J Epidemiol Community Health. doi: 10.1136/jech-2014-205263

68. Andreeva VA, Deschamps V, Salanave B, et al (2016) Comparison of Dietary Intakes Between a Large Online Cohort Study (Etude NutriNet-Santé) and a Nationally Representative Cross-Sectional Study (Etude Nationale Nutrition Santé) in France: Addressing the Issue of Generalizability in E-Epidemiology. Am J Epidemiol 184:660-669. doi: 10.1093/aje/kww016 
Table 1. Main characteristics of the sample across tertiles of proportion of organic food in the diet, $n=8,174$, NutriNet-Santé study ${ }^{a}$

\begin{tabular}{|c|c|c|c|c|}
\hline Characteristics & $\begin{array}{c}\text { Tertile } 1 \\
(n=2,724)\end{array}$ & $\begin{array}{c}\text { Tertile } 2 \\
(n=2,725)\end{array}$ & $\begin{array}{c}\text { Tertile } 3 \\
(n=2,725)\end{array}$ & $\begin{array}{l}\mathbf{P} \\
\text { trend }^{b}\end{array}$ \\
\hline $\begin{array}{l}\text { Proportion of organic food in the whole } \\
\text { diet (ratio) }\end{array}$ & $0.04(0.04)$ & $0.24(0.07)$ & $0.62(0.18)$ & $<0.0001$ \\
\hline Men $(\%)$ & 38.99 & 30.53 & 25.98 & $<0.0001$ \\
\hline Age (y) & $59.03(12.84)$ & $57.96(12.41)$ & $57.50(11.71)$ & $<0.0001$ \\
\hline Educational level (\%) & & & & $<0.0001$ \\
\hline Primary & 25.48 & 23.05 & 20.99 & \\
\hline High school diploma & 14.72 & 14.09 & 13.69 & \\
\hline University level or equivalent & 59.80 & 62.86 & 65.32 & \\
\hline Occupational status (\%) & & & & $<0.0001$ \\
\hline Retired & 56.06 & 51.01 & 47.05 & \\
\hline Employees & 9.14 & 9.69 & 9.69 & \\
\hline Intermediate profession & 10.61 & 12.48 & 12.4 & \\
\hline Managerial staff & 15.16 & 19.60 & 20.37 & \\
\hline Never employed & 7.60 & 6.24 & 8.55 & \\
\hline Self employed & 1.43 & 0.99 & 1.94 & \\
\hline Monthly income per household unit (\%) & & & & 0.49 \\
\hline Refuse to declare & 4.70 & 4.18 & 5.21 & \\
\hline $900-1200 €$ & 8.26 & 6.72 & 7.78 & \\
\hline $1200-1800 €$ & 20.15 & 19.63 & 20.15 & \\
\hline $1800-2700 €$ & 27.90 & 28.77 & 29.43 & \\
\hline$>2700 €$ & 38.99 & 40.70 & 37.43 & \\
\hline Location (\%) & & & & $<0.0001$ \\
\hline Rural community & 16.45 & 18.79 & 21.98 & \\
\hline $\begin{array}{l}\text { Urban unit with a population } \\
\text { smaller than } 20000 \text { inhabitants }\end{array}$ & 13.99 & 14.13 & 16.11 & \\
\hline $\begin{array}{l}\text { Urban unit with a population between } \\
20000 \text { and } 200000 \text { inhabitants }\end{array}$ & 15.16 & 16.59 & 16.00 & \\
\hline $\begin{array}{l}\text { Urban unit with a population } \\
\text { higher than } 200000 \text { inhabitants }\end{array}$ & 54.41 & 50.50 & 45.91 & \\
\hline Smoking habits (\%) & & & & 0.03 \\
\hline Never smoker & 46.26 & 47.63 & 50.61 & \\
\hline Former smoker & 44.35 & 43.89 & 43.08 & \\
\hline Current smoker & 9.40 & 8.48 & 6.31 & \\
\hline Physical activity level (\%) & & & & $<0.0001$ \\
\hline Low & 20.30 & 17.03 & 14.72 & \\
\hline Moderate & 40.42 & 42.06 & 39.60 & \\
\hline High & 39.28 & 40.92 & 45.69 & \\
\hline $\begin{array}{l}\text { Time lag between dietary data collection } \\
\text { and visit (months) }\end{array}$ & $23.90(11.38)$ & $22.99(11.39)$ & $22.17(11.36)$ & $<0.0001$ \\
\hline mPNNS-GS (/13.5) & $8.35(1.79)$ & $8.65(1.71)$ & $8.86(1.78)$ & $<0.0001$ \\
\hline Alcohol consumption (g/d) & $127.77(173.76)$ & $121.85(159.03)$ & $98.07(121.78)$ & $<0.0001$ \\
\hline
\end{tabular}




\begin{tabular}{lcccc} 
Energy intake (kcal/d) & $2032.06(644.43)$ & $2021.03(609.60)$ & $2027.76(617.92)$ & 0.80 \\
Carbohydrates $^{c}$ & $39.40(7.50)$ & $39.27(7.40)$ & $39.45(7.43)$ & 0.81 \\
Lipids $^{\mathrm{c}}$ & $40.70(6.88)$ & $41.20(6.92)$ & $42.38(7.27)$ & $<0.0001$ \\
Proteins $^{\mathrm{c}}$ & $19.51(3.58)$ & $19.13(3.45)$ & $17.80(3.48)$ & $<0.0001$ \\
$\mathrm{BMI}\left(\mathrm{kg} / \mathrm{m}^{2}\right)$ & $25.14(4.52)$ & $24.69(4.34)$ & $23.87(3.99)$ & $<0.0001$ \\
\hline
\end{tabular}

Abbreviations: BMI, Body Mass Index.

${ }^{\mathrm{a}}$ Values are means (SD) or percent, as appropriate.

${ }^{\mathrm{b}}$ Linear contrast test from ANCOVA (continuous variables) or Mantel-Haenszel $\mathrm{Chi}^{2}$ trend-test (categorical variables).

${ }^{c}$ As a percentage of alcohol-free energy intake. 
Table 2. Association between tertiles of proportion of organic food in the diet and MetS, $\mathrm{n}=\mathbf{8 , 1 7 4}$, NutriNet-Santé study ${ }^{\mathrm{a}}$

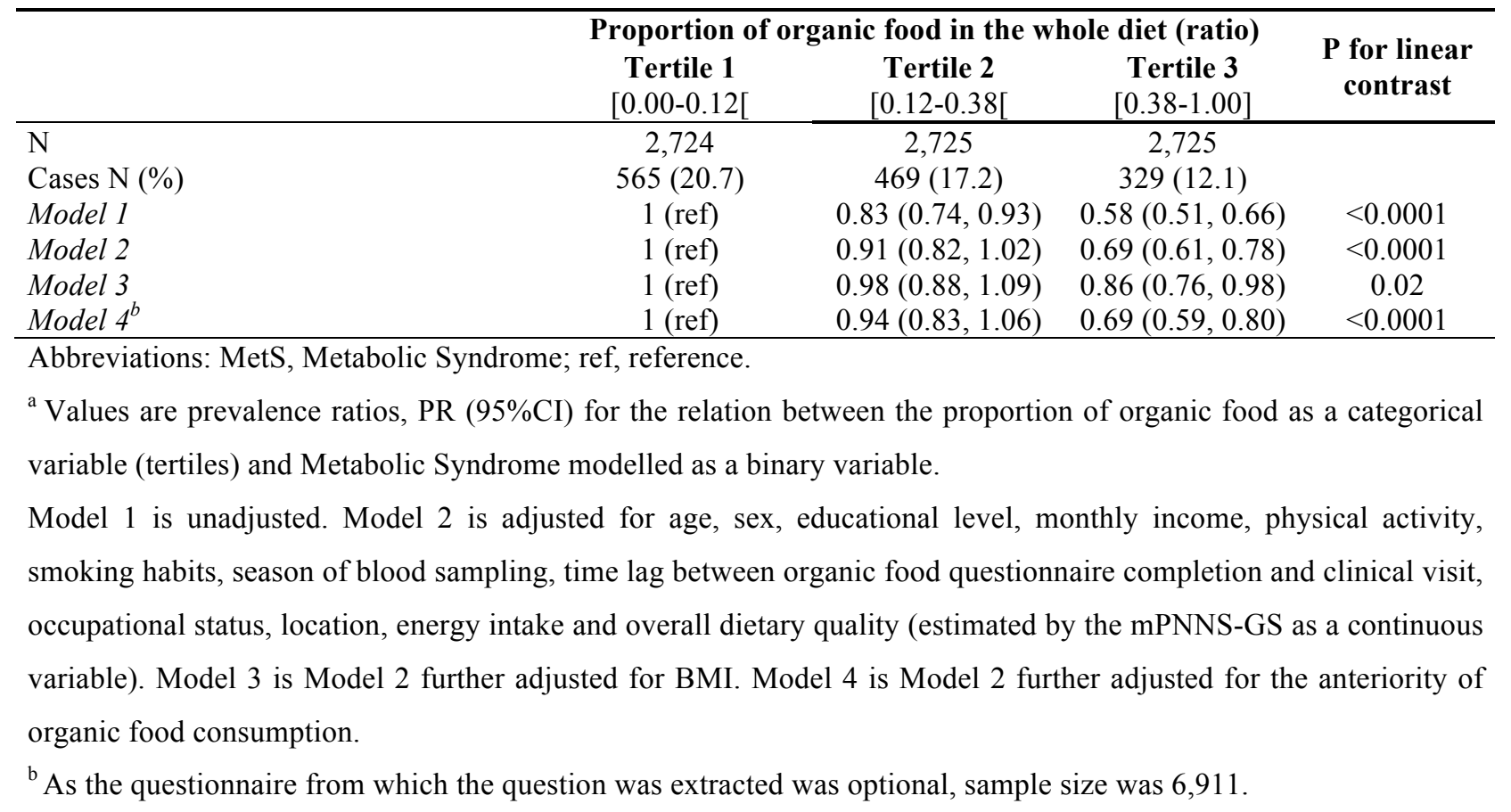


Table 3. Association between tertiles of proportion of organic food according to food groups and MetS, NutriNet-Santé study ${ }^{a}$

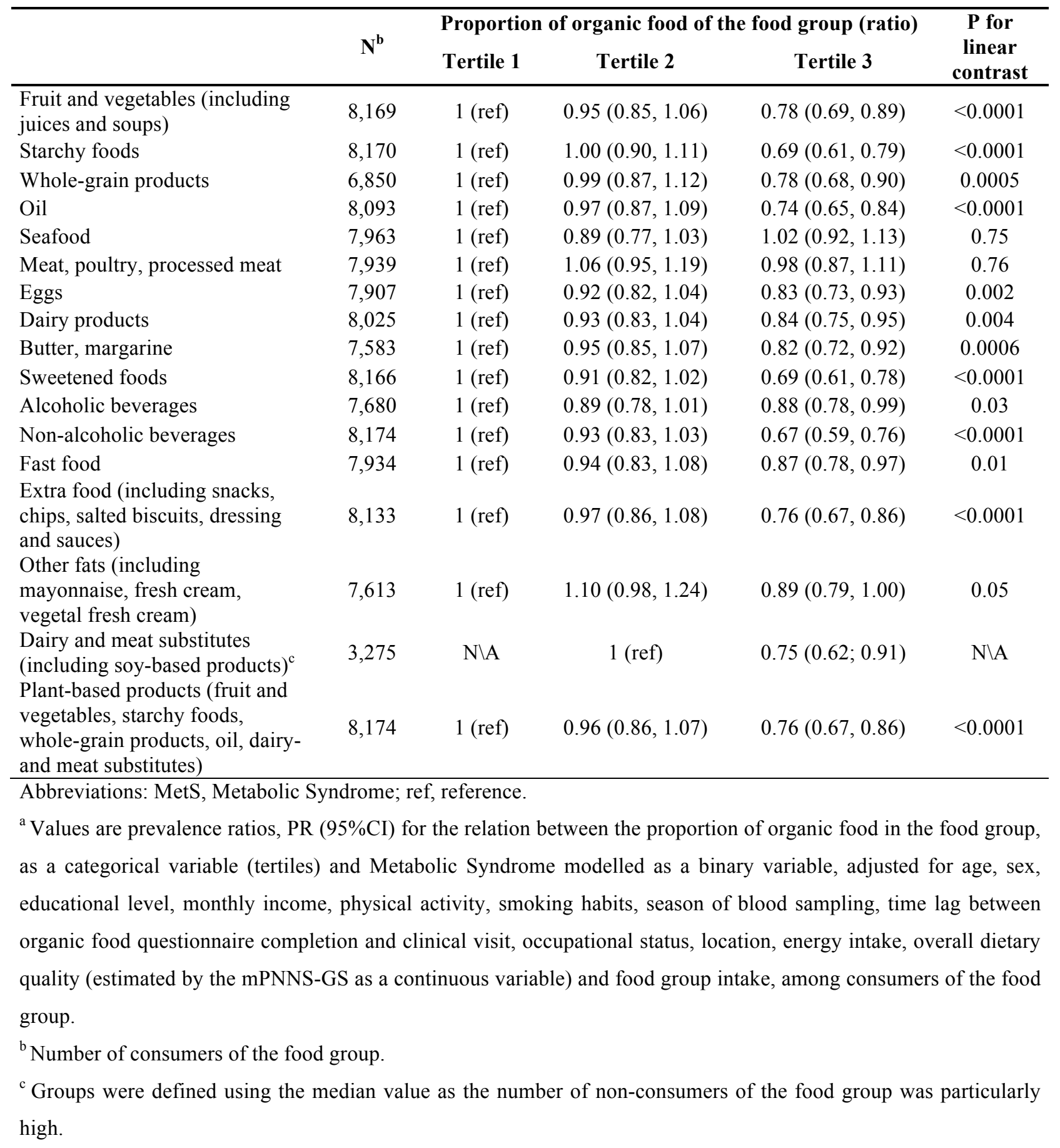


Table 4. Association between tertiles of proportion of organic food in the diet and metabolic traits, NutriNet-Santé study ${ }^{\mathrm{a}}$

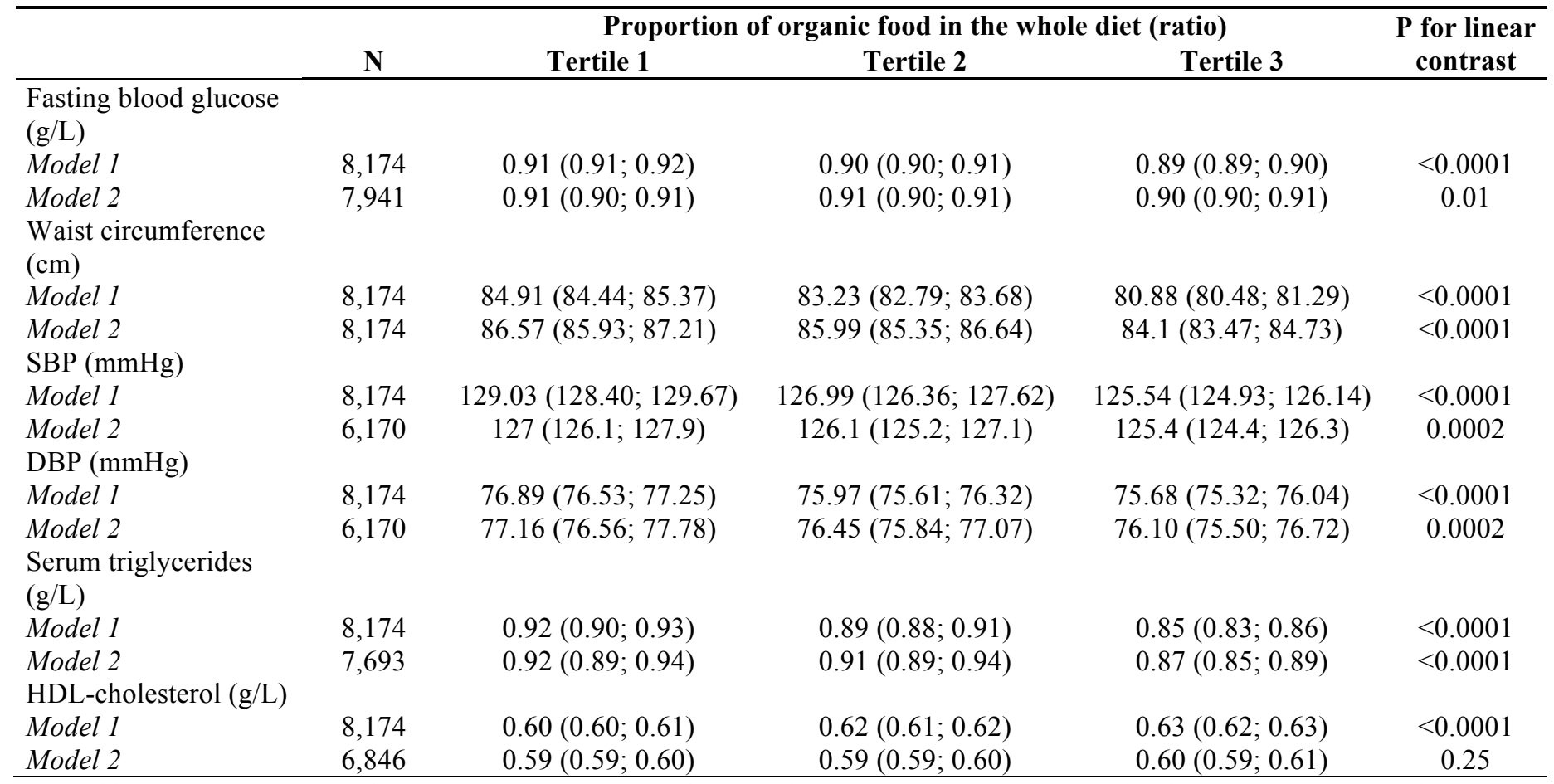

Abbreviations: BMI, Body Mass Index; SBP, Systolic Blood Pressure; DBP, Diastolic Blood Pressure; HDL, High Density Protein, LDL, Low Density Protein.

a Values are adjusted geometric means $(95 \% \mathrm{CI})$ for the relation between the proportion of organic food as a categorical variable (tertiles) and metabolic traits. P-value referred to log-transformed variables.

Model 1 is unadjusted. Model 2 is performed among sub-samples who are not taking any related medications for the specific outcome and is adjusted for age, sex, educational level, monthly income, physical activity, smoking habits, season of blood sampling, time lag between organic food questionnaire completion and clinical visit, occupational status, location, energy intake and overall dietary quality (estimated by the mPNNS-GS as a continuous variable). 
Figure 1. Association between the proportion of organic food in the diet (as a continuous variable) and MetS across subgroups, $n=8,174$, NutriNet-Santé study

Abbreviations: CI, Confidence Interval; mPNNS-GS, modified Programme Nationale Nutrition Santé Guideline Score; PR, Prevalence Ratios.

a Model adjusted for age, sex, educational level, monthly income, season of blood sampling, time lag between organic food questionnaire completion and clinical visit, occupational status, location, energy intake and overall dietary quality (estimated by the mPNNS-GS as a continuous variable) and all other variables presented in the Figure.

\section{Figure 1. Association between the proportion of organic food in the diet (as a continuous variable) and MetS across subgroups, $n=8,174$, NutriNet-Santé study}

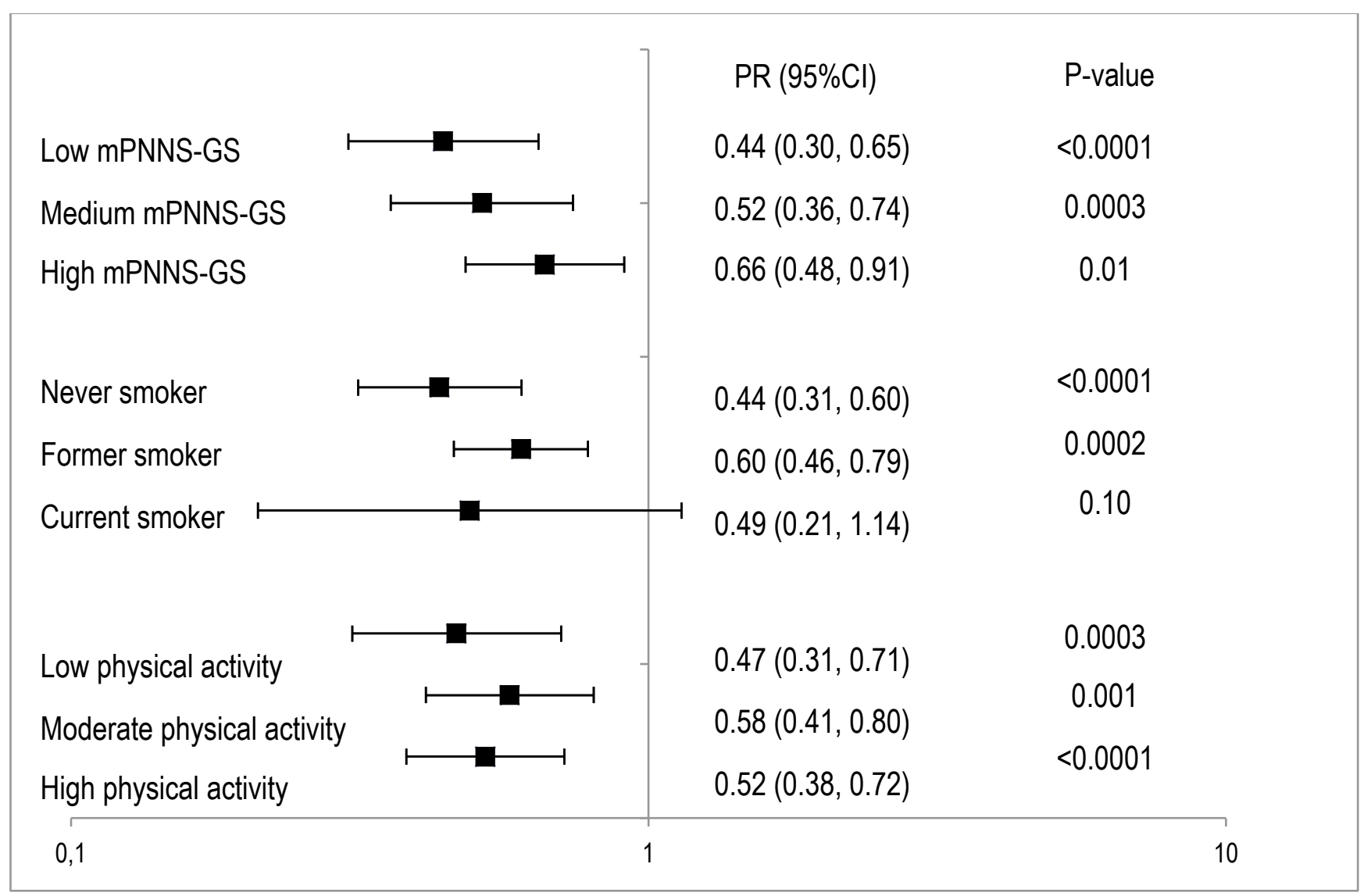

Abbreviations: CI, Confidence Interval; mPNNS-GS, modified Programme Nationale Nutrition Santé Guideline Score; PR, Prevalence Ratios.

${ }^{a}$ Model adjusted for age, sex, educational level, monthly income, season of blood sampling, time lag between organic food questionnaire completion and clinical visit, occupational status, location, energy intake and overall dietary quality (reflected by the mPNNS-GS as a continuous variable) and all other variables presented in the Figure. 
